\title{
$\angle$ Research Square \\ Exploring Higher Rates of Breastfeeding Among Civilian Military Wives: A Mixed Methods Study
}

Nicole Ringo ( $\nabla$ nringo@apu.edu )

Azusa Pacific University

Sheila M. Gephart

The University of Arizona

\section{Research}

Keywords: breastfeeding, breastfeeding self-efficacy, civilian military wives, concurrent mixed-method

Posted Date: April 2nd, 2021

DOI: https://doi.org/10.21203/rs.3.rs-365583/v1

License: (9) (1) This work is licensed under a Creative Commons Attribution 4.0 International License. Read Full License 


\section{Abstract}

Background: As compared to the United States general postpartum population, civilian military wives encounter unique challenges that can impede their ability to breastfeed, including geographic replacement and physical and emotional challenges. Yet despite these challenges, civilian military wives demonstrate higher rates of breastfeeding initiation and duration in the United States postpartum population as a whole. The purpose of this study was to explore factors contributing to the high rate of breastfeeding initiation and duration among civilian military wives and to determine what might be learned from these factors for intervention design for the broader population of postpartum mothers.

Methods: The sample consisted of 28 civilian military wives whose ages ranged from 18-45. The study was conducted online using a concurrent mixed-methods design.

Results: Seven main themes with 16 subthemes emerged from the descriptions of the semi-structured interviews. The results of the Breastfeeding Self-Efficacy Scale-Short Form score was $55.2(S D=5.73)$. The results of the integrative analysis revealed that factors within the military environment influence a sense of community, thus supporting their breastfeeding self-efficacy (BSE). Additionally, supportive and probreastfeeding healthcare facilitators (especially lactation consultants) throughout the prenatal, intrapartum, and postpartum periods described by civilian military wives were associated with high levels of breastfeeding self-efficacy among civilian military wives. Moreover, high levels of breastfeeding self-efficacy related to breastfeeding skills and duration were associated with the accessibility of resources within the military environment, breastfeeding health and economic benefits, and setting of a breastfeeding goal.

Conclusions: Using a concurrent mixed-methods design, this study identified facilitators from the descriptions of civilian military wives that they believed promote their higher rates of breastfeeding initiation and continuation, quantified their high level of breastfeeding self-efficacy, and identified descriptive factors that contributed to both areas lacking in the literature among this population.

\section{Introduction}

Leading breastfeeding authorities recommend breastfeeding exclusively for the first six months of a newborn's life. ${ }^{1}$ This recommendation derives from the holistic health benefits that breastfeeding provides for both mother and infant. ${ }^{2}$ Physical newborn health benefits can include protection from numerous chronic diseases, such as diabetes, obesity, allergies, and heart disease. ${ }^{3}$ Mental-emotional health benefits for breastfeeding mothers include maternal-newborn bonding and decreased symptoms of maternal depression. ${ }^{4}$ From a community perspective, breastfeeding provides economic advantages, as it partially or wholly supplants costly infant formula. ${ }^{5}$

The United States (U.S.) national rates of breastfeeding for initiation and duration to six months are $83.2 \%$ and $57.6 \% .{ }^{6}$ These remain below the Healthy People 2020 breastfeeding goals of $100 \%$ initiation and $60.6 \%$ continuation to six months. ${ }^{6,7}$ As compared to the U.S. general postpartum population, civilian military wives (CMWs) encounter unique challenges that can impede their ability to breastfeed, including geographic 
replacement and physical and emotional challenges. ${ }^{8}$ Yet despite these challenges, CMWs demonstrate higher rates of breastfeeding initiation and duration compared to the U.S. postpartum population as a whole. ${ }^{9,10,8}$

As of 2015, the Department of Defense (DoD) indicated that military active-duty and reserve members were married to 1,012,251 civilian spouses. ${ }^{11}$ This figure does not include unmarried partners or dual-military member marriages. Within military-affiliated communities, CMWs assume a unique role framed by the military core values, experience stress related to partner deployment, and demonstrate resilience despite these challenges. ${ }^{12}$ CMWs represent a unique group due to multiple factors, including younger marriages, geographical replacement, and family separation. ${ }^{12}$ Children of parents sent out on repeated deployments experience anxiety and decreased well-being. ${ }^{12} \mathrm{CMWs}$, on average, marry younger-between the 20 to 25 years of age in comparison to their non-military-affiliated civilian counterparts. ${ }^{12,13}$ Younger-age marriages correlate with higher divorce rates in both civilian and military populations. ${ }^{14} \mathrm{CMWs}$ are less likely to be employed than their non-military affiliated civilian counterparts and, if employed, on the whole, make less than their nonmilitary affiliated civilian counterparts. ${ }^{15}$

The lives of CMWs involve stress from deployments of their loved one to consequences of war as well as the regular challenges that couples of childbearing age encounter. ${ }^{12}$ Because military service demands geographic replacement, CMWs move more (2.4 times more) than their civilian counterparts. ${ }^{15}$ This geographic replacement can create a dual role of a tied migrant and a tied stayer. ${ }^{13}$ As a tied migrant, CMWs keep the family together by moving with the service member despite the loss of employment or educational situation. ${ }^{13}$ As a tied stayer following the move to be with the service member, CMWs are bound to the location of their spouse's assignment, limiting their ability to obtain a job or schooling. ${ }^{13}$ It can be argued that a dual marriage occurs between a CMW, her active-duty spouse, and the designated military branch. CMWs thus face challenges beyond those typically experienced by married, childbearing couples, including displacement from familiar resources and expectations. CMWs must uphold the same values as their military partners: honor, courage, and commitment. These unique context demands of CMWs require effective coping skills to manage the personal sacrifices they have made in support of their service member partner. ${ }^{16}$

CMWs encounter unique challenges that can impede their ability to breastfeed such as a lack of support due to geographical movement and physical and emotional challenges. ${ }^{12,8}$ Despite these challenges, CMWs demonstrate higher rates of breastfeeding initiation (92.2\%) and duration at six months (61.7\%) in comparison to the U.S. breastfeeding population initiation (83.2\%) and duration at six months (57.6\%) rates. ${ }^{6,9}$ This study provides descriptions of prevalent factors associated with breastfeeding and duration among CMWs as well as describes the types of breastfeeding resources CMWs felt were effective in meeting their breastfeeding goals. Additionally, this study examined breastfeeding self-efficacy in CMWs. The insight gained from exploring factors associated with higher rates of breastfeeding initiation and duration among CMWs has the potential to lead to the development and transferability of effective breastfeeding interventions.

\section{Purpose And Aims}

The purpose of this study was to explore factors contributing to the high rate of breastfeeding initiation and duration among CMWs and to determine what might be learned from these factors for intervention design for 
the broader population of postpartum mothers. Research aims were to: 1) Describe prevalent factors associated with breastfeeding initiation and duration among CMWs; 2) Examine breastfeeding self-efficacy (BSE) in CMWs and, 3) Identify attributes of breastfeeding facilitators that are reported by CMWs and to further identify which attributes of CMWs' BSE are associated with characteristics of the individual and which are associated with the military environment. The Health Promotion Model (HPM) guided this study by informing coding categories in the data analysis phase.

\section{Materials And Methods}

\section{Study Design}

Nola Pender's Health Promotion Model (HPM) provided theoretical guidance (for this study) into the potential transferable personal characteristics and experiences that affect breastfeeding behaviors of CMWs. Some examples of the transferable personal characteristics and experiences of CMWs included positive health behaviors that result in improved health, improved functional ability, and satisfaction with well-being at all stages of development. ${ }^{17}$ The HPM posits that several factors influence an individual's ability to engage in positive health behaviors which include: personal factors, perceived benefits of action, perceived barriers of action, perceived self-efficacy, activity related to affect, interpersonal influences, situational influences, commitment to plan of action, immediate competing demands and preferences, and health promoting behavior. ${ }^{18}$ The results from the literature review and the HPM were used to inform the interview guide and study design.

A concurrent mixed-methods design was used; it is a type of design in which qualitative and quantitative data were collected in parallel, analyzed separately, and then merged to best understand the research problem. ${ }^{19}$ Snowball sampling was used to recruit participants from a Facebook site devoted to supporting breastfeeding among active-duty and civilian military wives. ${ }^{20}$ From the Facebook site, potential informants were directed to a Qualtrics link. Potential informants completed a five-item survey that included inclusion and exclusion criteria as well as sample questions to review which offered potential informants' insight about questions that were asked of them.

Sensitive security issues revolved around CMWs and the nature of their partners' active-duty situation or the military-affiliated community as well as their breastfeeding experience that could increase stress and anxiety within the study participants. A disclaimer in Qualtrics indicated that participants at any time may choose not to answer a question (for any reason) or further participate in the study. This disclaimer allowed the potential participants to withdraw from the study and continue to receive the Amazon gift cards in the event they did not want to continue with the study. Confidentiality of participant information was a primary focus and concern during this study. Therefore, any information gathered from the participants was solely shared with the dissertation committee members. Once the informant had been identified as an eligible participant via Qualtrics, she was sent an invite for an initial meeting via email. Contact was made through email to obtain study consent and to determine the informants' availability for their qualitative interview meeting via Zoom.

\section{Measures}


The Breastfeeding Self-Efficacy Scale-Short Form (BSES-SF) was used to identify the degree of a CMW's confidence in her ability to carry out breastfeeding or breastfeeding self-efficacy. ${ }^{21}$ Interview data gathered from the participants supported the exploration into the unique breastfeeding facilitators among CMWs. The interviews were conducted via Zoom. The rationale for conducting virtual interviews is that social media promotes access to hard-to-reach, geographically displaced populations. ${ }^{22}$ The quantitative component of this study was a cross-sectional, retrospective descriptive, non-experimental design, whereby the researcher investigated the level of breastfeeding self-efficacy among CMWs.

\section{Analysis}

Qualitative content analysis was used to analyze the data retrieved from the semi-structured interviews. Quantitative data analysis involved first measuring the reliability of the BSES-SF to determine internal coherence and homogeneity within the measurement tool. Cronbach's Alpha (a) was assessed to determine internal consistency. Descriptive statistics from the socio-demographic characteristic questionnaire and the mean BSES-SF score as well as the individual items scores were analyzed. The results were compared with the results from Dennis's original BSES scale research as well as more recent scores from other BSE studies within the literature. A meta-matrix approach was used to perform analytic integration of the qualitative and quantitative analysis. Matrices assist with the identification of patterns of regularities and anomalies and promote a fuller exploration of all the data simultaneously. ${ }^{23}$

\section{Results}

\section{Sample Characteristics}

The sample (Table 1) consisted of $(n=28)$ CMWs whose ages ranged from 18-45. The majority of the sample (50\%) reported being between 28-33 years of age. The second largest age group reported an age group ranging from $22-27$ (28.6\%). About $78.6 \%$ of the sample identified as Caucasian; $3.6 \%$ identified as African American; $10.7 \%$ identified as Hispanic; 3.6\% identified as Asian; and, 3.6\% identified as other. 
Table 1

Socio-demographic characteristics of sample.

\begin{tabular}{|c|c|}
\hline & $N(\%)$ \\
\hline \multicolumn{2}{|l|}{ Age } \\
\hline $18-21$ & $3.6 \%$ \\
\hline $22-27$ & $28.6 \%$ \\
\hline $28-33$ & $50.0 \%$ \\
\hline $34-38$ & $14.3 \%$ \\
\hline $39-45$ & $3.6 \%$ \\
\hline \multicolumn{2}{|l|}{ Delivery Method } \\
\hline Vaginal & $78.6 \%$ \\
\hline Cesarean Section & $21.4 \%$ \\
\hline \multicolumn{2}{|l|}{ Delivery Complications } \\
\hline Yes & $21.4 \%$ \\
\hline No & $78.6 \%$ \\
\hline \multicolumn{2}{|c|}{ Number of Infants delivered } \\
\hline Singleton & $92.9 \%$ \\
\hline Twins & $3.6 \%$ \\
\hline Triplets & $3.6 \%$ \\
\hline \multicolumn{2}{|c|}{ Gestational Age at Delivery } \\
\hline $38-41$ weeks & $78.6 \%$ \\
\hline \multicolumn{2}{|l|}{ First Time Delivery } \\
\hline No & $75 \%$ \\
\hline Yes & $25 \%$ \\
\hline \multicolumn{2}{|c|}{ Biological Sex of Infant Born this Delivery } \\
\hline Male & $64.3 \%$ \\
\hline Female & $32.1 \%$ \\
\hline Male \& Male (Twins) & $3.6 \%$ \\
\hline \multicolumn{2}{|l|}{ Maternal Ethnicity } \\
\hline Caucasian & $78.6 \%$ \\
\hline African American & $3.6 \%$ \\
\hline
\end{tabular}




\begin{tabular}{|c|c|}
\hline & $\mathrm{N}(\%)$ \\
\hline Hispanic & $10.7 \%$ \\
\hline Asian & $3.6 \%$ \\
\hline Other & $3.6 \%$ \\
\hline \multicolumn{2}{|l|}{ Marital Status } \\
\hline Married & $100 \%$ \\
\hline \multicolumn{2}{|l|}{ Military Branch } \\
\hline Army & $39.3 \%$ \\
\hline Navy & $10.7 \%$ \\
\hline Air Force & $42.9 \%$ \\
\hline Marine Corps & $3.6 \%$ \\
\hline Coast Guard & $3.6 \%$ \\
\hline \multicolumn{2}{|l|}{ Military Rank } \\
\hline Enlisted & $82 \%$ \\
\hline Officer & $18 \%$ \\
\hline \multicolumn{2}{|l|}{ Level of Education } \\
\hline Higher Degree & $42.9 \%$ \\
\hline Completed College & $32.1 \%$ \\
\hline Some College & $14.3 \%$ \\
\hline Completed High School & $10.7 \%$ \\
\hline \multicolumn{2}{|l|}{ Household Income } \\
\hline$\$ 20,000-\$ 50,000$ & $35.7 \%$ \\
\hline$\$ 50,000-\$ 100,000$ & $53.6 \%$ \\
\hline$\varnothing \$ 100,000$ & $10.7 \%$ \\
\hline \multicolumn{2}{|l|}{ Initiated Breastfeeding } \\
\hline In hospital & $100 \%$ \\
\hline \multicolumn{2}{|c|}{ Supplemented with Formula } \\
\hline Yes & $17.9 \%$ \\
\hline No & $82.1 \%$ \\
\hline If Supplemented, When & \\
\hline
\end{tabular}




\begin{tabular}{|lc|}
\hline \multicolumn{1}{|l|}{ Week 1 } & N (\%) \\
\hline Month 4 & $75 \%$ \\
\hline Relocation Prior to Pregnancy, During Pregnancy, or 6 Months After Delivery \\
\hline Yes & $39.3 \%$ \\
\hline No & $60.7 \%$ \\
\hline If Relocated, When & $9.1 \%$ \\
\hline Prior to Pregnancy & $36.4 \%$ \\
\hline During Pregnancy & $54.5 \%$ \\
\hline
\end{tabular}

\section{Qualitative Findings}

The experiences described by breastfeeding CMWs that contribute to their higher rates of breastfeeding were demonstrated from the qualitative portion of this study. However, there were similarities in their perspectives and descriptions of military life and breastfeeding experience (hectic but worthwhile), military community facilitators, healthcare facilitators, breastfeeding benefits, determination of a breastfeeding goal, supportive resources, and providing advice from others. The theme Contrary Case represents isolated situations that did not conform to the positive findings described by the participants (Table 2).

Table 2. Themes and Exemplar Quotations. 


\section{Themes $\quad$ Exemplar Quotations}

1. Hectic "It's really hard [what is it like in general to be a CMW]. It's hard because you never know, but you don't have any consistency in your life, and a lot of time, your own careers and things

Worthwhile like that have to stop because you have to move and everything. It's hard being away from

Subthemes: your family, not having as much help as you would if you were at home. But it's also great. I like it..."

$1 \mathrm{a}$.

Challenges

2a. Rewards

\section{Military}

Community

Facilitators

Subthemes:
"Everybody just assumes that standard here [breastfeeding in a military community] like it's not rare for somebody to be breastfeeding for two years." "But I feel like it's just a much more welcoming environment because more people are aware of the situation [what it is like to be a breastfeeding CMW] like there's just a lot of kids around all the time."

2a. Way of

Life

2b. Attitudes

Toward

Breastfeeding

3.

Healthcare

Facilitators

Subthemes:

3a. TRICARE

3b.

Supportive

Providers and

Nurses
"Well, I think part of [what helped sustain breastfeeding greater than six months related to the military healthcare structure] is that the pediatricians at each base that we've been to, and we've seen-sometimes, you don't always get to see your same pediatrician. All of them are super supportive of breastfeeding, even extended breastfeeding, when I was weary about it." "The nurses were fantastic. They were friendly. They didn't just make small talk on and they were informative and they listen when I said when I would be concerned about something. When I had any question they waited, you know, hear the question before they started answering they didn't dismiss anything you know right away they seemed genuine."

\section{Breast is Best}

Subthemes:

4a. Health

Benefits

4b. Cost-

effective

\section{5. \\ Breastfeeding}

Goal

Subthemes:

5a. Duration and

Perseverance

$5 b$.

Overcoming
"So [the reason I chose to breastfeed was because] I'm just very exposed to breastfeeding in general and the benefits of breastfeeding. I feel like I just felt like something. If you want to provide your baby with the optimal, you know, nutrition and the optimal start in life. I just feel like breastfeeding has so many benefits." "And I mean, also, just like I feel like it's the most beneficial in every way, even from a cost saving perspective, like you don't have to buy formula."
"It's what I wanted to do and I knew I wanted to do it for a year and no less than that. So, when it was hard in the beginning [I didn't want to stop or let anything stop me from breastfeeding] and I think it was really just my perseverance. I think that kept me going, because I think it would be easy just to give up. I think I'm just a very research type of person. And it's, yeah, the research is clear [about the importance of health benefits from breastfeeding and why knowing that helped me to persevere with breastfeeding]." 
6.

Resources

Subthemes:

6a. Support

Groups

6b. Social

Media

6c. Lactation

Consultants

$6 d$.

Breastfeeding

Peers

7. Advice for Others

Subthemes:

7a. Prepare

for

Breastfeeding

7b. Stick with

it

\section{Contrary}

Case
"There's a lot of support groups [including breastfeeding and military wife specific that helped support my breastfeeding duration]. Mom2Mom support groups that you can go too. And they've also got La Leche League here and actually somebody in our, our neighborhood. We live on base and one of the leaders is also a military wife. So, there's actually a whole lot of support for breastfeeding here." "Support with the lactation consultants [helped with breastfeeding continuation past six months] because that I mean is a huge resource, especially when you don't know if they're getting enough, you know, especially with your first child." "So, it was good to have someone Ilike another CMW] that was also breastfeeding." "[l would tell other breastfeeding CMWs to] take it day by day or hour by hour or whatever is going to get you through it. However, take it slowly if you need to be successful. Every milestone is a win, right, and then I would tell them, you know you will get through the day to day. Find yourself, whatever your support lyou will need such as] groups going to be, so if it's going to be a friend, even if it's someone that you have to call on the phone. There's a resource here."
"Um, [my experience having a baby and breastfeeding in a military hospital] was very horrible, to be honest. And my first pregnancy, I saw a doctor that was unbelievably rude and very forgetful. He was very old and the hospital would not transfer me out of his service, then I changed the type of TRICARE that we had. So, I could see a civilian provider, because the clinic was still... it was just overworked and they were so busy, it was too crazy and there wasn't enough quality care." 
Table 3

Comparison of BSES-SF among CMW to other studies.

\begin{tabular}{|c|c|c|c|}
\hline BSES-SF Questions & $\begin{array}{l}\text { Dennis \& Faux Mean } \\
\text { (1999) }\end{array}$ & $\begin{array}{l}\text { Rowe } \\
\text { (2015) }\end{array}$ & CMWs \\
\hline Determine that my baby is getting enough milk & $3.71(1.08)$ & $4.0(1.1)$ & 4.14(.71) \\
\hline $\begin{array}{l}\text { Successfully cope with breastfeeding like I have with } \\
\text { other challenging tasks }\end{array}$ & $4.04(.95)$ & $3.91(1.2)$ & $4.07(.64)$ \\
\hline Breastfeeding my baby without using formula & $4.11(1.25)$ & $3.21(1.5)$ & $4.29(.85)$ \\
\hline $\begin{array}{l}\text { Ensure that my baby is properly latched on for the whole } \\
\text { feeding }\end{array}$ & $4.01(.98)$ & $3.79(1.4)$ & 4.18(.61) \\
\hline Be satisfied with my breastfeeding & $4.01(.97)$ & $3.85(1.3)$ & 4.44(.51) \\
\hline $\begin{array}{l}\text { Deal with the fact that breastfeeding can be time } \\
\text { consuming }\end{array}$ & $3.91(.95)$ & $4.0(1.2)$ & $4.18(.82)$ \\
\hline $\begin{array}{l}\text { Finish feeding my baby on one breast before switching to } \\
\text { the other breast }\end{array}$ & $3.96(.97)$ & $3.97(1.2)$ & $4.18(.91)$ \\
\hline $\begin{array}{l}\text { Mange to keep up with my baby's breastfeeding } \\
\text { demands }\end{array}$ & $4.03(1.0)$ & $3.52(1.4)$ & 4.32(.61) \\
\hline
\end{tabular}


Table 4

Meta-Matrix: Qualitative, quantitative and integrative findings.

\begin{tabular}{|c|c|c|}
\hline $\begin{array}{l}\text { Qualitative } \\
\text { Theme }\end{array}$ & $\begin{array}{l}\text { Quantitative } \\
\text { Question }\end{array}$ & Integrative Interpretation \\
\hline $\begin{array}{l}\text { Resources \& } \\
\text { Healthcare } \\
\text { Facilitators }\end{array}$ & $\begin{array}{l}\text { Q51: } \\
\text { Determine } \\
\text { that my baby } \\
\text { is getting } \\
\text { enough milk }\end{array}$ & $\begin{array}{l}\text { Based on their determination of adequate milk consumed by their baby, } \\
\text { accessibility of breastfeeding resources \& healthcare facilitators } \\
\text { supported CMWs' higher levels of BSE. When questioning the sufficiency } \\
\text { of their milk supply, CMWs sought out advice from supportive pro- } \\
\text { breastfeeding healthcare professionals, especially Lactation } \\
\text { Consultations. These professionals provided breastfeeding support } \\
\text { through education, management of poor latch, and reassurance. }\end{array}$ \\
\hline
\end{tabular}

Hectic but Q52:

Worthwhile Successfully cope with breastfeeding

like I have with other challenging tasks
CMWs have a high degree of positive coping ability and willingness to take on and overcome challenging day-to-day tasks for the sake of their family and their spouse's job. Although, breastfeeding can present them with challenges, they take it on without any hesitation. CMWs translate and use these attributes to take on breastfeeding challenges and do whatever it takes to persevere and overcome those breastfeeding challenges.

\section{Q53:}

Breast is Best

\& Military Community

Facilitators

Resources \& Healthcare Facilitators, Advice for Others

Hectic but Worthwhile \& Military Community Facilitators
Breastfeeding my baby without using formula

Q54: Ensure that my baby is properly latched on for the whole feeding

\section{Q55: Manage} the breastfeeding situation to my satisfaction
The prominent reasons described by CMWs for breastfeeding were breastfeeding health benefits and cost-effectiveness. The third reason that reinforces BSE in this area is how breastfeeding and extended breastfeeding are positively accepted within the military environment. $88 \%$ of the sample reported extended breastfeeding.

Utilizing specific breastfeeding resources that provide immediate help such as social media, nurse help lines, and pro-breastfeeding healthcare professional as well applying the advice from other CMWs are strategies that help to increase their confidence that their infant is properly latched.
With all of the extra day-to-day challenges as a result of spousal deployment or forced geographical movement, CMWs described strategies used to manage breastfeeding during these situations. CMWs described that the mobility of breastfeeding as well as not having to deal with formula and bottles allows them to manage situations of spousal deployment and forced geographical movement. Additionally, support from other military families and maintaining their commitment during these challenging situations increased their feelings of accomplishment and satisfaction with management of the situation.
Resources, Hectic but Worthwhile \& Military Community Facilitators
Q56: Manage to breastfeed even if my baby is crying

CMWs described a multi-faceted approach for how they manage challenging breastfeeding situations. For example, seeking out Lactation Consultants, social media, and vicariously breastfeeding through peers. This was apparent during the interviews. During the interview if their infant started to cry and tug at them, they effortlessly started to breastfeed their infant. CMW attributes of multi-tasking due to their hectic life and feeling the freedom to breastfeed within their environment contribute to their ability to manage breastfeeding even if their infant is crying.

Breastfeeding Q57: Keep Goal wanting to breastfeed
Having breastfeeding goals assists CMWs with achievement of a primary breastfeeding duration of one year. However, recommendations from the $\mathrm{WHO}$ and the acceptance within the military environment further supports their desire to extend breastfeeding duration. 


\begin{tabular}{|c|c|c|}
\hline $\begin{array}{l}\text { Qualitative } \\
\text { Theme }\end{array}$ & $\begin{array}{l}\text { Quantitative } \\
\text { Question }\end{array}$ & Integrative Interpretation \\
\hline $\begin{array}{l}\text { Military } \\
\text { Community } \\
\text { Facilitators }\end{array}$ & $\begin{array}{l}\text { Q58: } \\
\text { Breastfeed } \\
\text { with my } \\
\text { family } \\
\text { members } \\
\text { present }\end{array}$ & $\begin{array}{l}\text { For the CMWs, the military is their current family. CMWs felt free to } \\
\text { breastfeed uncovered on and off the base. CMWs described facilitators } \\
\text { that contributed to their confidence to breastfeed in front of their military } \\
\text { family members include the sense of respect that is felt and manifested } \\
\text { within the military environment and the acceptance that is a standard } \\
\text { way of life within this environment. }\end{array}$ \\
\hline $\begin{array}{l}\text { Hectic but } \\
\text { Worthwhile \& } \\
\text { Breastfeeding } \\
\text { goal }\end{array}$ & $\begin{array}{l}\text { Q59: Be } \\
\text { satisfied with } \\
\text { my } \\
\text { breastfeeding }\end{array}$ & $\begin{array}{l}\text { CMWs described that being them has its challenges, but also there is a } \\
\text { payoff or rewards for being them. They endure the hard work, embrace } \\
\text { the suck, and reap the rewards of travel, feelings of pride for their spouse } \\
\text { and the duties he performs for the sake of their country. CMWs also } \\
\text { describe their sense of pride with accomplishing and extending } \\
\text { breastfeeding goals. }\end{array}$ \\
\hline $\begin{array}{l}\text { Resources \& } \\
\text { Healthcare } \\
\text { Facilitators }\end{array}$ & $\begin{array}{l}\text { Q61: Finish } \\
\text { feeding my } \\
\text { baby on one } \\
\text { breast before } \\
\text { switching to } \\
\text { the other } \\
\text { breast }\end{array}$ & $\begin{array}{l}\text { A prominent resource that CMWs described as increasing their } \\
\text { confidence with breastfeeding skill techniques were Lactation } \\
\text { Consultants, Midwives, and Pediatricians. All were essential in educating } \\
\text { and reassuring CMWs performed proper breastfeeding skill techniques. }\end{array}$ \\
\hline $\begin{array}{l}\text { Resources \& } \\
\text { Military } \\
\text { Community } \\
\text { Facilitators }\end{array}$ & $\begin{array}{l}\text { Q62: Mange } \\
\text { to keep up } \\
\text { with my } \\
\text { baby's } \\
\text { breastfeeding } \\
\text { demands }\end{array}$ & $\begin{array}{l}\text { CMWs described various facilitators that were instrumental in managing } \\
\text { to keep up with their demands of breastfeeding such as Lactation } \\
\text { Consultants, support groups, social media, and breastfeeding peers. } \\
\text { Additionally, military families support each other during times of } \\
\text { difficulty. For example, bringing meals and giving baby showers to assist } \\
\text { CMW's experiences during times of breastfeeding demands. }\end{array}$ \\
\hline
\end{tabular}

\section{Quantitative Findings}

The findings from the quantitative statistical analysis demonstrate that CMWs have high levels of BSE. Descriptive statistics revealed reliability that was previously shown was supported in this study and with this sample. When mean item statistics was compared with the BSES item statistics shown in other samples by Dennis ${ }^{21}$ and Rowe ${ }^{24}$, the results of CMWs were higher showing higher levels of BSE among CMW in our sample compared to others.

\section{Integrative Analysis Findings}

The integrative analysis revealed that factors within the military environment influence a sense of community, thus supporting their BSE in these areas. Additionally, supportive and pro-breastfeeding healthcare facilitators (especially lactation consultants) throughout the prenatal, intrapartum, and postpartum periods described by CMWs were associated with their high level of BSE. Moreover, high levels of BSE related to breastfeeding skills and duration were associated with the accessibility of resources within the military environment, breastfeeding health and economic benefits, and setting of a breastfeeding goal.

\section{Discussion}

The current study added to the existing literature by exploring the relationship of factors that contribute to higher levels of breastfeeding self-efficacy among CMWs and those factors described by CMWs that contribute to their higher breastfeeding rates. The predominant themes of hectic but worthwhile, military community 
facilitators, healthcare facilitators, breast is best, breastfeeding goal, resources, advice for others can inform the development of future nursing interventions to support higher rates of breastfeeding for other populations. Breastfeeding benefits, having a breastfeeding goal, freedom to choose their healthcare provider and delivery facility, accessibility of supportive resources such as La Leche League support groups, lactation consultants, social media, and peer-mentors were highly valued and described by CMWs in this study as contributing to their high level of BSE and breastfeeding duration. Therefore, the integration of the prominent themes (and subthemes) into interventions that target lower BSE in other populations has the potential to improve breastfeeding initiation and duration among those population.

\section{Strengths}

A mixed methods approach was used for this study. According to Field ${ }^{25}$ "Mixed methods potentially offer depth of qualitative understanding with the reach of quantitative techniques". The BSES-SF provided quantifiable validation that CMWs in this study experienced higher levels of BSE. Moreover, CMWs in this study demonstrated higher levels of BSE when participants' means were compared with the BSE item statistics found in Dennis Breastfeeding Self-Efficacy Scale ${ }^{21}$ and Rowe ${ }^{24}$. However, the findings from the BSES-SF alonewas insufficient to identify factors that contributed to higher levels of BSE within the sample. The qualitative arm of this study provided reasons described by the participants that contributed to their high level of BSE. Teddlie and Tashakkori ${ }^{26}$ warn that despite the type of mixed methods research design employed by a researcher, an enhanced understanding will only result if the research strands are effectively integrated together through a systematic process. In this study, a convergent validation of the findings resulted from the systematic integration process using a meta-matrix.

\section{Limitations}

The prominent race represented in this study were Caucasians (78\%) who outnumbered $3.6 \%$ of the sample who identified as African American, 10.7\% identified as Hispanic, 3.6\% identified as Asian, and 3.6\% identified as other. Within the breastfeeding literature, ethnic disparities reflect those of under-represented ethnic groups. ${ }^{27}$ Breastfeeding provides health and psychosocial benefits for all mothers, but minority mothers are disproportionately affected by adverse health outcomes that can be improved by breastfeeding. ${ }^{27}$ Other notable areas reflecting a lack of diversity within the sample included educational level, household income, military branch, and military rank. Simply put, the respondents were better educated, had more financial resources and higher rank than the general population of CMWs which could limit the application of our findings to all CMWs. Another limitation was that a technical oversight contributed to the participants not filling out one of the BSES-SF 14-items. The item not addressed by the participants was / can always continue to breastfeed my baby for every feeding. Based on the overall BSES-SF mean score of 55.2, the omission of this item may have impacted the overall score and comparability to other studies. For that reason, we report individual item response means compared to other studies and did not explicate in great detail the whole scale results.

\section{Implications}


There is limited data about the higher rates of breastfeeding of civilian military wives within the literature. Future CMW breastfeeding studies should aim to recruit samples that reflect ethnic diversity, educational level, household income, military branch, and military rank and have larger sample sizes, especially for asking quantitative questions.

\section{Conclusion}

Nurses play a pivotal role in the delivery of health education and possess the power to support positive health practices as well as to promote disease prevention behaviors. Breastfeeding is a health promotion activity that provides physical and psychosocial benefits for both the mother and her infant. ${ }^{2}$ For these reasons, leading maternal and newborn health organizations have endorsed breastfeeding as a preferred feeding method because of its numerous health benefits. ${ }^{28,1,7}$ The U.S. national rates of breastfeeding for initiation and duration to six months are $83.2 \%$ and $57.6 \%$. These remain below the Healthy People 2020 breastfeeding goals of $100 \%$ initiation and $60.6 \%$ continuation to six. ${ }^{6,7}$ Over the past 20 years, the Breastfeeding Friendly Initiative has improved breastfeeding outcomes. ${ }^{29}$ However, more strategies are needed to improve breastfeeding outcomes to meet the recommended breastfeeding goals.

\section{Abbreviations}

BSE: Breastfeeding Self-Efficacy

BSES-SF: Breastfeeding Self-Efficacy Scale-Short Form

CDC: Centers for Disease Control and Prevention

CMWs: Civilian Military Wives

DoD: Department of Defense

HPM: Health Promotion Model

U.S.: United States

\section{Declarations}

\section{Ethics approval and consent to participate:}

The study protocol was approved by the Institutional Review Board at the University of Arizona in compliance with all applicable Federal regulations governing the protection of human subjects. Protocol Number: 1905663025

\section{Consent for publication:}

Consent for publication was obtained from all of the participants

\section{Availability of data and materials:}


Data are the property of the authors and can be obtained by contacting the Principal Investigator: Nicole Ringo, PhD, MSN/ED, BSN, RN; email: nringo@apu.edu

\section{Competing interests:}

The authors declare that they have no competing interests.

\section{Funding:}

Not applicable

Author's contributions: Only individuals who made significant contributions were selected as authors. NR and SG contributed equally to this work. NR conceived the research question. NR collected the data and performed a literature search. NR and SG performed the statistical analysis. NR wrote the first draft of the manuscript. All authors revised the first draft of the manuscript and made substantial contributions to the final version for submission. The authors read and approved the final manuscript.

\section{Acknowledgements:}

Not applicable

\section{Authors' information:}

Not applicable

\section{References}

1. Centers for Disease Control and Prevention. Breastfeeding: National policies and positions. Available at https://www.cdc.gov/breastfeeding/pdf/2018breastfeedingreportcard.pdf; accessed on July 18, 2018.

2. Victoria CG, Bahl R, Barros AJD, et al. Breastfeeding in the 21 st century: Epidemiology, mechanisms, and lifelong effect. Lancet. 2016;387(10017):475-90. doi:10.1016/so140-6736(15)01024-7.

3. Kelishadi R, Farajian S. The protective effects of breastfeeding on chronic non- communicable diseases in adulthood: A review of evidence. Adv Biomed Res. 2014;3(3):1-5. doi:10.4103/2277-9175.12462.

4. Hahn-Holbrook J, Haselton MG, Dunkel Schetter C, Glynn LM. Does breastfeeding offer protection against maternal depressive symptomatology? Archives of Women's Mental Health. 2013;16(5):411-22. doi:10.1007/s00737-013-0348-9.

5. Tensteps.org. Benefits of breastfeeding for the environment and society. Available at http://www.tensteps.org/benefits-of-breastfeeding-for-the-environment-society.shtml; accessed on June 15, 2016.

6. Centers for Disease Control and Prevention. Breastfeeding report card. Available at https://www.cdc.gov/breastfeeding/data/reportcard.htm; accessed on July 18, 2018.

7. Office of Disease Prevention and Health Promotion. Maternal, infant, and child health. In Healthy People 2020. Available at https://www.healthypeople.gov/2020/topics-objectives/topic/maternal-infant-andchild-health/objectives; accessed on March 18, 2016. 
8. Mao CY, Narrang S, Lopreiato J. Breastfeeding practices in military families: A 12-month prospective population-based study in the national capital region. Mil Med. 2012;177(2):239-234.

doi:10.7205/milmed-d-11-00181.

9. Haas DM, Howard CS, Christopher M, Rowan K, Broga MC, Corey T. Assessment of breastfeeding practices and reasons for success in a military community hospital. Journal of Human Lactation. 2006;22(4):43945. doi:10.1177/0890334406293163.

10. Lundquist J, Zhun X, Barfield W, Elo I. Do black-white racial disparities in breastfeeding persists in the military community? Maternal Child Health Journal. 2015;19(2):419-27. doi:10.1007/s10995-014-1524-X.

11. Militaryonesource.com. The new parent support program. Available at https://www.militaryonesource.mil/-/the-new-parent-supportprogram?inheritRedirect=true; accessed on July 16, 2018.

12. Clever M, Segal DR. The demographics of military children and families. Future Child. 2013;23(2):13-39. doi:10.1353/foc. 2013.0018 .

13. Lundquist J, Xu Z. Reinstitutionalizing families: Life course policy and marriage in the military. Journal of Marriage Family. 2014;76(5):1063-81. doi:10.1111/jomf.12131.

14. Military.com. Young military marriage - right choice? Available at https://www.military.com/spouse/relationships/military-marriage/young-military-marriage-rightchoice.html; accessed on July 16, 2018.

15. Ross SM. 21st century American military families: A review in the context of the wars in Afghanistan and Iraq. Sociology Compass. 2014;8(5):888-902. doi:10.1111/soc4.12168.

16. Eubanks T. Life as a military spouse. Urologic Nursing. 2013;33(2):97-9. doi:10.7257/1053816X.2013.33.2.97.

17. Pender NJ, Murdaugh CL, Parsons MA. Health promotion in nursing practice. Ed 6. Boston: Pearson; 2010.

18. Pender NJ: Health promotion model manual, Ann Arbor, MI: University of Michigan, 2011. Available at https://deepblue.lib.umich.edu/bitstream/handle/2027.42/85350/HEALTH_PROMOTION_MANUAL_Rev_52011.pdf.

19. Creswell JW, Creswell JD. Research design: Qualitative, quantitative, and mixed methods approach, Ed 5. Thousand Oaks: SAGE Publications, Inc.; 2018.

20. Mom2momglobal.org: Available at https://www.mom2momglobal.org/; accessed July 19, 2016.

21. Dennis CL, Faux S. Development and psychometric testing of the breastfeeding self-efficacy scale. Res Nurs Health, 1999; 22(5): 399-409. Available at https://doi.org/10.1002/(SICI)1098-

240X(199910)22:5\%3C399::AID-NUR6\%3E3.0.C0;2-4.

22. lacono VL, Symonds P, Brown DHK. (2016). Skype as a tool for qualitative research interviews. Sociological Research Online, 2016; 21(2): 1-15. doi:10.5153/sro.3952.

23. Polit DF, Beck CT. Nursing research: Generating and assessing evidence for nursing practice. Ed 10. Philadelphia: Lippincott Williams and Wilkins; 2017.

24. Rowe S: Breastfeeding self-efficacy in a sample of WIC participants, 2015. Available at https://digitalcommons.gardner-webb.edu/nursing_etd/214/; accessed October 18, 2018.

25. Field A. Discovering statistics using IBM SPSS statistics, Ed 4. Los Angeles: SAGE Publications; 2013. 
26. Teddlie C, Tashakkori A. Foundations of mixed methods research: Integrating quantitative and qualitative approaches in the social and behavioral sciences. Thousand Oaks: SAGE Publications, Inc; 2009.

27. Jones KM, Power ML, Queenan JT, Schlukin J. Racial and ethnic disparities in breastfeeding. Breastfeeding Medicine. 2015;10(4):186-96. doi:10.1089/bfm.2014.0152.

28. American Academy of Pediatrics: Breastfeeding. Available at https://www.aap.org/en-us/advocacy-andpolicy/aap-health-initiatives/Breastfeeding/Pages/default.aspx; accessed March 12, 2018.

29. Munn AC, Newman SD, Mueller M, Phillips SM, Taylor SN. The impact in the United States of the babyfriendly hospital initiative on early infant health and breastfeeding outcomes. Breastfeeding Medicine. 2016;11(5):220-30. doi:10.1089/bfm.2015.0135. 